\title{
Economic Burden of Herpes Zoster and Post-Herpetic Neuralgia in Adults 60 Years of Age or Older: Results from a Prospective, Physician Practice-Based Cohort Study in Kushiro, Japan
}

\author{
Hiroyuki Nakamura ${ }^{1} \cdot$ Akiko Mizukami $^{2} \cdot$ Koichi Adachi $^{3} \cdot$ Sean Matthews $^{4}$. \\ Katsiaryna Holl $^{2,4}$ - Kazuhiro Asano ${ }^{5}$ Akihiro Watanabe ${ }^{6}$ - Riri Adachi ${ }^{7}$. \\ Mariko Kiuchi $^{8} \cdot$ Keiju Kobayashi $^{9}$ Keiko Sato ${ }^{2}$ Taizo Matsuki ${ }^{2}$. \\ Toshihiko Kaise $^{2} \cdot$ Desmond Curran $^{4}$
}

Published online: 7 October 2017

(C) The Author(s) 2017. This article is an open access publication

\begin{abstract}
Background and Objective Herpes zoster has a high incidence rate among people aged $\geq 60$ years and can lead to serious complications such as post-herpetic neuralgia. There are currently no data on the economic burden of herpes zoster and post-herpetic neuralgia in Japan, and the objective of this study was to address this gap.
\end{abstract}

Akiko Mizukami

akiko.mizukami@gsk.com

1 Kushiro City General Hospital, 1-12, Shunkodai, Kushiro, Hokkaido 085-0822, Japan

2 Development and Medical Affairs Division, GSK, GSK Bldg. 6-15, Sendagaya 4-chome, Shibuya-ku, Tokyo 151-8566, Japan

3 Kushiro Dermatology Clinic, 1-5-8, Aikokunishi, Kushiro, Hokkaido 085-0057, Japan

4 Health Economics Department, GSK, 20, Avenue de Flemming, 1300 Wavre, Belgium

5 Asano Skin Clinic, 3-9-5, Showaminami, Kushiro, Hokkaido 084-0909, Japan

6 Sakuragaoka Dermatology Clinic, 1-10-27, Sakuragaoka, Kushiro, Hokkaido 085-0805, Japan

7 Adachi Dermatology Cosmetic Surgery Clinic, 8-1, Suehirocho, Kushiro, Hokkaido 085-0014, Japan

8 Kushiro Daiichi Hospital, 4-11-10, Tottoriodori, Kushiro, Hokkaido 084-0906, Japan

9 Kushiro Red Cross Hospital, 21-14, Shineicho, Kushiro, Hokkaido 085-8512, Japan
Methods A total of 412 patients aged $\geq 60$ years diagnosed with herpes zoster were recruited. Demographic, clinical, and healthcare resource utilization data on patients with herpes zoster or post-herpetic neuralgia collected via case report forms were used to estimate direct medical cost. Data obtained from a questionnaire survey among patients with herpes zoster/post-herpetic neuralgia were used to estimate transportation cost and productivity loss.

Results The mean number of outpatient visits was 5.7. Prescription medications were the main cost driver accounting for $60 \%$ of the direct medical cost. The mean direct medical and total herpes zoster-related costs per patient were $¥ 43,925$ and $¥ 57,112$, respectively, and were higher in patients with post-herpetic neuralgia than in those with herpes zoster without complications. Direct medical cost represented $77 \%$, productivity loss $19 \%$, and transportation cost $4 \%$ of the total.

Conclusions This is the first study of the economic burden of herpes zoster and post-herpetic neuralgia in Japan and it demonstrated substantial direct medical cost as a result of the multiple outpatient visits and prescription medications required. These findings provide baseline data for possible future economic evaluations of new herpes zoster/postherpetic neuralgia interventions.

Trial registration This cost analysis is part of a prospective, physician practice-based cohort study conducted between June 2013 and February 2015 in Kushiro, Japan (Clinicaltrials.gov identifier NCT01873365, registered on 6 June, 2013). 


\section{Key Points}

Herpes zoster and its serious complication, postherpetic neuralgia, are frequent among people aged $\geq 60$ years.

This study investigated the economic burden of herpes zoster and post-herpetic neuralgia in Japanese patients aged $\geq 60$ years: direct medical, nonmedical, and indirect costs were examined.

Outpatient visits and prescription medications were responsible for the majority of direct medical costs.

This is the first investigation of the economic burden of herpes zoster and post-herpetic neuralgia in Japan.

\section{Introduction}

Herpes zoster (HZ) occurs when varicella-zoster virus reactivates as a result of waning of cell-mediated immunity. The anti-varicella-zoster virus antibody is reported to be prevalent in more than $90 \%$ of the Japanese population aged $\geq 20$ years [1] and is associated with a $30 \%$ lifetime risk of developing $\mathrm{HZ}$ [2]. Herpes zoster-related pain resolves after approximately 90 days for many patients with HZ, but an estimated $20 \%$ will develop post-herpetic neuralgia (PHN) [3], a debilitating long-lasting pain that can continue for months or years, requiring long-term analgesic treatment. Annually, about 500,000 individuals aged $\geq 60$ years develop HZ in Japan [3, 4]. This number is expected to increase owing to the aging population with an expected increase in the proportion of people aged $\geq 60$ years from $32 \%$ in 2012 to $41 \%$ by 2050 [5]. This may potentially increase the economic burden of $\mathrm{HZ}$ and PHN on the healthcare system, elderly population, and their caregivers.

The economic burden of $\mathrm{HZ}$ and PHN has been studied in many countries [6-12], and these studies demonstrate that both HZ and PHN impose a substantial economic burden on the healthcare system and society. The direct medical cost of managing $\mathrm{HZ}$ represents a substantial proportion of the total HZ-related cost, with even higher costs for patients experiencing PHN. Indirect costs owing to sick leave (absenteeism) for patients and caregivers were also considerable [9]. Predictors of higher direct medical costs seemed to be older age, co-morbidities and immunosuppression, duration of hospitalization, use of medications, and the severity of symptoms. Being employed predicted higher indirect costs [13].

To date, no data on health resource utilization and cost owing to HZ in Japan have been published. The objective of this study was to estimate the economic burden of $\mathrm{HZ}$ and its complications on the healthcare system and society at large in Japan.

\section{Methods}

\subsection{Study Design}

Cost data were collected as part of an observational, prospective, physician practice-based cohort study of people aged $\geq 60$ years conducted in Kushiro, Japan between June 2013 and February 2015. Four hundred and twelve patients were eligible for the cost analysis. This is the reporting of secondary outcomes for this study that has been previously reported [14].

Study participants were recruited from patients presenting at seven dermatology clinics or hospitals. Herpes zoster was diagnosed by the physician at the initial consultation or at a subsequent visit within 7 days of the initial consultation. The maximum follow-up time for each patient was 270 days from the initial visit. At 90 days after the initial visit, patients with a pain score of 0 were considered as having completed the study. Patients with a pain score of $\geq 1$ at 90 days after the initial visit were followed for an additional 90 days and assessed again 180 days after study entry. Patients with a persisting pain score of $\geq 1$ at 180 days were followed for a further 90 days with final follow-up at 270 days after the initial visit. Clinically relevant PHN was defined by the presence of HZ-related pain rated as $\geq 3$ in response to Item 3 of the Zoster Brief Pain Inventory questionnaire, persisting or occurring more than 90 days after $\mathrm{HZ}$ rash onset [15].

This study is registered at ClinicalTrials.gov (NCT01873365) and was conducted in accordance with ethical guidelines [16] and was reviewed by an independent ethics committee. Written informed consent was obtained from all enrolled participants.

\subsection{Data Collection}

With the exception of hospitalizations covered by the Diagnosis Procedure Combination/Per-Diem Payment System (DPC/PDPS), healthcare resource utilization data were collected via standardized case report forms at every visit to estimate the direct medical cost for treating $\mathrm{HZ}$ and PHN. Demographic data and clinical characteristics of the $\mathrm{HZ}$ cases were also collected. For hospitalizations covered by DPC/PDPS, the admission and discharge dates and the disease code for DPC were recorded. Questionnaire surveys were completed at pre-scheduled time points to estimate HZ-related costs other than the direct medical cost. Transportation information such as mode and distance 
between the healthcare facility and the patient's home was collected on the first questionnaire survey to estimate transportation costs. Data concerning patients' and their caregivers' HZ-related absences from work were also obtained from the questionnaire survey at $0,15,30,60,90$, $120,150,180,210,240$, and 270 days after the initial visit to estimate the indirect cost (productivity loss). Data were collected from the initial visit until completion of the study for each patient.

\subsection{Cost Estimation}

Costs were divided into three categories: direct medical costs, direct non-medical costs, and indirect costs. Direct medical costs were collected from a payer's perspective. In addition, direct non-medical and indirect costs were collected to estimate the societal costs. Summary statistics of total cost and of each cost component were calculated and presented by age group and $\mathrm{HZ}$ status. Patients were assigned a $\mathrm{HZ}$ status in one of three categories: $\mathrm{HZ}$ without any complications, HZ with PHN, and HZ with complications but no PHN.

DPC/PDPS is a comprehensive payment system based on a medical fee point schedule of DPC on medical care for acute-phase hospitalizations in Japan. Direct medical costs were calculated based on the 2014 revision of the medical fee point scheme, DPC/PDPS [17] and National Health Insurance drug prices [18]. One medical fee point is equivalent to ¥10. All hospitalization costs were obtained from hospitals applying the DPC/PDPS system.

Direct medical costs were composed of outpatient visits, hospitalizations, medications, and outpatient procedures. The total cost was calculated by combining the total of these cost components. Costs were calculated using the following formulas:

(1) For outpatient visits, the total sum was calculated based on ([medical fee points for each service $] \times 10)+$ total sum of ([unit drug price] $\times$ amounts);

(2) For hospitalizations covered by DPC/PDPS, the total sum was calculated based on ([DPC points per day for each day $] \times 10)+$ total sum of ([the meal fee] $\times 3 \times$ [no. of days admitted -1$]$ ). Costs for hospitalizations not covered by DPC/PDPS were calculated the same way as for outpatient visits.

The following assumptions were made for the cost calculations:

(1) Only the prescription sheet fees for outpatients were added to the costs of the prescribed medicines for each prescription. The dispensing-related costs at the pharmacy were not included.
(2) Management fees for specific dermatologic diseases were added once a month for the outpatient visits and beyond 1 month after the initial visit.

(3) General blood tests were assumed to be included with the general hematologic test, biochemistry test for ten items, and immunological test for $\mathrm{C}$-reactive protein, as non-HZ-specific items were not collected individually.

(4) Referral fees were added if the patient was referred to another medical institute by a physician.

Transportation costs were estimated as direct nonmedical costs related to the HZ episode. Costs were calculated based on the mode of transportation and the total number of kilometers $(\mathrm{km})$ traveled. Unit cost per $\mathrm{km}$ traveled was obtained from online information (taxi [19], private car [20], bus [21], and train [22]). The fuel efficiency of a private car was assumed to be $15 \mathrm{~km} / \mathrm{L}$. The total cost was calculated by using the formula [unit cost per $\mathrm{km}$ traveled] $\times$ [distance between healthcare facility and home] $\times 2 \times$ [number of visits].

The data collected for distance traveled were incomplete. Imputations for missing data were based on the median distance traveled for the patients with data, stratified by residence (outside or inside Kushiro). Some patients indicated that they used other forms of transport. The transport cost for those patients was imputed based on the median transport cost per residence (outside or inside Kushiro). If a patient indicated using more than one form of transport, the costs were calculated by dividing the total number of journeys equally between the modes of transport used.

The indirect cost was estimated as productivity loss calculated by the number of working days lost for the patients and their caregivers. For patients' productivity loss, the cost was calculated based on the patient's salary. A basic survey of wage structure was used to calculate the hourly wage stratified by gender and age for patients who did not provide their salary information and all their caregivers [23]. If incomplete data on the number of working days lost or caregivers' gender and age were collected, the missing data were imputed as the median or average of the available data.

Healthcare resource utilization was expressed as the number of patients, percentage of the total number of patients, and mean frequency. The mean and standard deviation were calculated for all costs. The median, minimum, and maximum were also calculated for direct medical costs. All costs were expressed in Japanese yen [¥] as of 2014 or based on the latest information available (US\$1 = ¥105.9). 
Table 1 Patient demographics

\begin{tabular}{|c|c|c|c|c|c|c|c|c|c|c|}
\hline \multirow[t]{2}{*}{ Age group (years) } & \multicolumn{2}{|c|}{$\begin{array}{l}60-64 \\
N=92\end{array}$} & \multicolumn{2}{|c|}{$\begin{array}{l}65-69 \\
N=85\end{array}$} & \multicolumn{2}{|c|}{$\begin{array}{l}70-79 \\
N=163\end{array}$} & \multicolumn{2}{|c|}{$\begin{array}{l}\geq 80 \\
N=72\end{array}$} & \multicolumn{2}{|c|}{$\begin{array}{l}\text { Total } \\
N=412\end{array}$} \\
\hline & $n$ & $\%$ & $n$ & $\%$ & $n$ & $\%$ & $n$ & $\%$ & $n$ & $\%$ \\
\hline \multicolumn{11}{|l|}{ Gender } \\
\hline Male & 40 & 43.5 & 34 & 40.0 & 65 & 39.9 & 25 & 34.7 & 164 & 39.8 \\
\hline Female & 52 & 56.5 & 51 & 60.0 & 98 & 60.1 & 47 & 65.3 & 248 & 60.2 \\
\hline \multicolumn{11}{|l|}{ Occupation } \\
\hline Employed: full-time & 35 & 38.0 & 10 & 11.8 & 11 & 6.7 & 1 & 1.4 & 57 & 13.8 \\
\hline Employed: part-time & 8 & 8.7 & 10 & 11.8 & 4 & 2.5 & 0 & 0 & 22 & 5.3 \\
\hline Self-employed & 6 & 6.5 & 3 & 3.5 & 6 & 3.7 & 1 & 1.4 & 16 & 3.9 \\
\hline Not employed (housewife/unemployed/retired) & 42 & 45.7 & 57 & 67.1 & 137 & 84.0 & 66 & 91.7 & 302 & 73.3 \\
\hline Others & 1 & 1.1 & 3 & 3.5 & 1 & 0.6 & 0 & 0 & 5 & 1.2 \\
\hline Data not available & 0 & 0 & 2 & 2.4 & 4 & 2.5 & 4 & 5.6 & 10 & 2.4 \\
\hline \multicolumn{11}{|l|}{ Residence } \\
\hline Kushiro & 77 & 83.7 & 74 & 87.1 & 138 & 84.7 & 63 & 87.5 & 352 & 85.4 \\
\hline Outside Kushiro & 15 & 16.3 & 11 & 12.9 & 25 & 15.3 & 9 & 12.5 & 60 & 14.6 \\
\hline \multicolumn{11}{|l|}{ Complications $^{\mathrm{a}}$} \\
\hline No complication & 83 & 90.2 & 73 & 85.9 & 126 & 77.3 & 58 & 80.6 & 340 & 82.5 \\
\hline Dermatological & 3 & 3.3 & 3 & 3.5 & 13 & 8.0 & 2 & 2.8 & 19 & 4.6 \\
\hline Ocular & 0 & 0 & 0 & 0 & 5 & 3.1 & 1 & 1.4 & 6 & 1.5 \\
\hline Neurological & 1 & 1.1 & 2 & 2.4 & 10 & 6.1 & 3 & 4.2 & 16 & 3.9 \\
\hline PHN & 5 & 5.4 & 7 & 8.2 & 20 & 12.3 & 6 & 8.3 & 38 & 9.2 \\
\hline
\end{tabular}

PHN post-herpetic neuralgia

${ }^{\text {a }}$ Some patients had more than one complication

\subsection{Complying with Ethics of Experimentation}

All procedures performed in studies involving human participants were in accordance with the ethical standards of the institutional and/or national research committee and with the 1964 Helsinki Declaration and its later amendments or comparable ethical standards.

\section{Results}

\subsection{Patient Demographics}

Patient demographics are presented in Table 1. Of the 412 patients, $33.7 \%$ were housewives, $39.6 \%$ were unemployed/retired, and 23\% were employed. The employment rate was higher $(53 \%)$, in the 60-64 years age group compared with other age groups. Dermatological, ocular, and neurological complications as a result of $\mathrm{HZ}$ were observed in 19 (4.6\%), $6(1.5 \%)$, and $16(3.9 \%)$ patients, respectively. Post-herpetic neuralgia was experienced by 38 patients $(9.2 \%)$.

\subsection{Direct Medical Cost}

The healthcare resource utilization and cost by category are shown in Table 2. Patients came for a total of 2351 outpatient visits, i.e., a mean of 5.7 visits per patient. The mean number of outpatient visits increased with age from 4.8 to 7.1 . Twelve patients $(2.9 \%)$ were referred to specialists such as ophthalmologists, ear-nose-throat physicians, orthopedists, and dermatologists, eight (1.9\%) patients were hospitalized with a mean duration of stay amounting to 9.4 days. The mean cost per-patient hospitalized was $¥ 233,146$.

All patients were prescribed at least one type of medication and approximately 50\% received injections or ointments at the outpatient practice. The proportion of patients receiving both injections and ointments tended to increase with age. Costs for injections and ointments at the outpatient practice were highest in the $\geq 80$ years age group, whereas costs for medications were highest in the 70-79 years age group.

At the outpatient practice, the most commonly used injections and ointments were an extract from cutaneous tissue of rabbit inoculated with vaccinia virus, namely, 
Table 2 Healthcare resource utilization and cost by category

\begin{tabular}{|c|c|c|c|c|c|}
\hline Age group (years) & $\begin{array}{l}60-64 \\
N=92\end{array}$ & $\begin{array}{l}65-69 \\
N=85\end{array}$ & $\begin{array}{l}70-79 \\
N=163\end{array}$ & $\begin{array}{l}\geq 80 \\
N=72\end{array}$ & $\begin{array}{l}\text { Total } \\
N=412\end{array}$ \\
\hline \multicolumn{6}{|l|}{ Outpatient visit } \\
\hline$n$ & 92 & 85 & 163 & 72 & 412 \\
\hline Frequency (days) & 4.8 & 4.8 & 6.1 & 7.1 & 5.7 \\
\hline Mean cost $[¥]$ & 5562 & 5507 & 6408 & 7293 & 6188 \\
\hline \multicolumn{6}{|l|}{ Hospitalization } \\
\hline$n^{\mathrm{a}}$ & 0 & 2 & 6 & 0 & 8 \\
\hline Days/event & - & 8.5 & 9.7 & - & 9.4 \\
\hline Mean cost $[¥]$ & & 215,980 & 238,869 & & 233,146 \\
\hline \multicolumn{6}{|c|}{ Medications/Prescriptions } \\
\hline$n$ & 92 & 85 & 163 & 72 & 412 \\
\hline Mean cost $[¥]$ & 24,252 & 27,257 & 27,690 & 25,307 & 26,416 \\
\hline \multicolumn{6}{|l|}{ Injections } \\
\hline$n$ & 45 & 34 & 86 & 41 & 206 \\
\hline Frequency (times) & 5.0 & 4.8 & 5.9 & 6.7 & 5.7 \\
\hline Mean cost $[¥]$ & 2637 & 2638 & 3462 & 3499 & 3153 \\
\hline \multicolumn{6}{|l|}{ Ointment treatment } \\
\hline$n$ & 46 & 39 & 76 & 40 & 201 \\
\hline Frequency (times) & 2.1 & 2.2 & 2.5 & 3.5 & 2.5 \\
\hline Mean cost $[¥]$ & 1679 & 1659 & 2043 & 2937 & 2063 \\
\hline \multicolumn{6}{|l|}{ Other procedures } \\
\hline$n$ & 65 & 61 & 134 & 60 & 320 \\
\hline Mean cost $[¥]$ & 5156 & 4927 & 5493 & 6048 & 5421 \\
\hline
\end{tabular}

${ }^{a}$ The number of events was the same as the number of patients
Neurotropin ${ }^{\circledR} \quad$ [Nippon Zoki Pharmaceutical Co. Ltd, Osaka, Japan] (206 patients, 50\%) and vidarabine (141 patients, 34.2\%), respectively (Table 3). The majority of patients $(97.3 \%)$ were prescribed antivirals (prescriptions during hospitalization were not included): 264 patients $(64.1 \%)$ were prescribed valaciclovir hydrochloride, 202 (49.0\%) vidarabine, and 128 (31.1\%) famciclovir. Acetaminophen was the most commonly used analgesic $(50.5 \%)$ followed by pregabalin $(32.3 \%)$. Other medications prescribed to relieve pain or treat cutaneous symptoms are listed in Table 3.

With regard to other procedures, 159 (39\%) patients underwent blood testing for general medical assessment and $\mathrm{HZ}$ diagnosis and the antibody titers against varicellazoster virus were measured for $95(23 \%)$ patients. Ophthalmological and otorhinolaryngological examinations were observed in three patients and one patient, respectively. Additional procedures reported were medial nerve block (one patient) and xenon photo therapy (one patient). The mean cost for other procedures tended to increase with age.

Prescriptions including medications and prescription fees accounted for approximately $60 \%$ of the direct medical costs (Fig. 1a). Overall direct medical costs were highest in individuals aged 70-79 years. The direct medical cost for HZ with PHN or HZ with complications and no PHN was higher than that in $\mathrm{HZ}$ without any complications (Fig. 1b). The difference between HZ with PHN and HZ without any complications was mainly owing to medication and outpatient visit costs. In addition, the difference between $\mathrm{HZ}$ with complications and no PHN and $\mathrm{HZ}$ without any complications was based on the number of patients hospitalized.

\subsection{Direct Non-Medical Cost}

For transportation to the medical facility, 304 (74\%) patients used a private car, $44(11 \%)$ took a taxi, $31(7 \%)$ walked, $20(5 \%)$ took a bus, and $9(2 \%)$ used another form of transportation. The mean distance between patients' homes and the facility was $10.1 \mathrm{~km}$ after imputation. Direct non-medical costs (transportation costs) based on the mode of transport and the distance after imputation were per person on average (standard deviation) $¥ 1788$ (5221) for patients aged 60-64 years, ¥1464 (3491) for patients aged 65-69 years, ¥2684 (8622) for patients aged $70-79$ years, 
Table 3 Commonly used medications by category

\begin{tabular}{|c|c|c|c|c|c|}
\hline \multirow[t]{2}{*}{ Category } & \multicolumn{2}{|c|}{$\begin{array}{l}\text { Total } \\
N=412\end{array}$} & \multirow[t]{2}{*}{ Medication } & \multicolumn{2}{|c|}{$\begin{array}{l}\text { Total } \\
N=412\end{array}$} \\
\hline & $n$ & $\%$ & & $n$ & $\%$ \\
\hline \multirow[t]{2}{*}{ Injections } & 206 & 50.0 & $\begin{array}{l}\text { An extract from cutaneous tissue of rabbit inoculated with vaccinia } \\
\text { virus }\end{array}$ & 206 & 50.0 \\
\hline & & & Glycyrrhizin/glycine/cysteine & 45 & 10.9 \\
\hline \multirow[t]{2}{*}{ Ointment treatment $^{\mathrm{b}}$} & 201 & 48.8 & Vidarabine & 141 & 34.2 \\
\hline & & & Betamethasone valerate/gentamicin sulfate & 50 & 12.1 \\
\hline \multicolumn{6}{|l|}{ Prescription $^{c}$} \\
\hline \multirow[t]{3}{*}{ Antivirals } & 401 & 97.3 & Valaciclovir hydrochloride & 264 & 64.1 \\
\hline & & & Vidarabine & 202 & 49.0 \\
\hline & & & Famciclovir & 128 & 31.1 \\
\hline \multirow[t]{2}{*}{ Analgesics } & 277 & 67.2 & Acetaminophen & 208 & 50.5 \\
\hline & & & Pregabalin & 133 & 32.3 \\
\hline \multirow[t]{2}{*}{ Drugs for acid-related disorders } & 217 & 52.7 & Rebamipide & 168 & 40.8 \\
\hline & & & Sodium gualenate hydrate/L-glutamine & 40 & 9.7 \\
\hline $\begin{array}{l}\text { Topical products for joint and muscular } \\
\text { pain }\end{array}$ & 147 & 35.7 & Naproxen & 116 & 28.2 \\
\hline Vitamin $B_{12}$ and folic acid & 138 & 33.5 & Mecobalamin & 138 & 33.5 \\
\hline \multirow[t]{3}{*}{ Other dermatological preparations } & 112 & 27.2 & Dimethyl isopropylazulene + bacitracin/fradiomycin sulfate & 67 & 16.3 \\
\hline & & & Bacitracin/fradiomycin sulfate & 45 & 10.9 \\
\hline & & & Dimethyl isopropylazulene & 42 & 10.2 \\
\hline \multirow{2}{*}{$\begin{array}{l}\text { Anti-inflammatory and antirheumatic } \\
\text { products }\end{array}$} & 111 & 26.9 & Loxoprofen sodium hydrate & 72 & 17.5 \\
\hline & & & Suprofen & 44 & 10.7 \\
\hline $\begin{array}{l}\text { Corticosteroids, dermatological } \\
\text { preparations }\end{array}$ & 78 & 18.9 & Betamethasone valerate/gentamicin sulfate & 70 & 17.0 \\
\hline \multirow[t]{3}{*}{ All other therapeutics } & 58 & 14.1 & $\begin{array}{l}\text { An extract from cutaneous tissue of rabbit inoculated with vaccinia } \\
\text { virus }\end{array}$ & 25 & 6.1 \\
\hline & & & Aconic acid & 19 & 4.6 \\
\hline & & & Goreisan & 16 & 3.9 \\
\hline Vitamins & 53 & 12.9 & Octotiamine $/ \mathrm{B}_{2} / \mathrm{B}_{6} / \mathrm{B}_{12}$ & 46 & 11.2 \\
\hline
\end{tabular}

Category $\mathrm{n}$ represents the number of patients reporting at least one medicine at the specified category. Medication $\mathrm{n}$ represents the number of patients using the specified drug

${ }^{\text {a }}$ Except for a category of all other therapeutics, medications used in 40 or more patients are listed. Thus, the total sum of Medication $\mathrm{n}$ does not reach to Category $n$

${ }^{\mathrm{b}}$ Ointments categorized into Ointment treatment were given at the clinic/hospital

${ }^{c}$ Medications categorized into Prescription include prescribed ointments or oral drugs

$¥ 3161$ (8627) for patients aged $\geq 80$ years, and $¥ 2316$ (7147) for all age groups combined.

\subsection{Indirect Cost}

The number of patients reporting HZ-related work absences was 28, with an average of 7.6 days of work lost (Table 4). All of these patients were aged $<80$ years. Thirty-seven patients reported being cared for by a total of 40 caregivers. Unsurprisingly, receiving care from family was more common for elderly patients. Twenty caregivers were working and reported a mean of 6.5 days of work lost because of an $\mathrm{HZ}$ episode. Non-working caregivers lost 11.6 days and those with missing data regarding employment status lost 11.3 days (Table 4).

Overall productivity losses calculated based on work absences and their wages were on average (standard deviation) $¥ 6456(20,809), ¥ 10,887 \quad(68,421)$, $¥ 12,146$ $(59,344)$, $¥ 13,611(50,234)$, and $¥ 10,872(53,694)$ per event in the age groups 60-64, 65-69, 70-79, $\geq 80$ years, and all age groups combined, respectively (Fig. 2). Productivity 
Fig. 1 Breakdown of direct medical costs by a age group and $\mathbf{b}$ herpes zoster (HZ) status. $P H N$ post-herpetic neuralgia

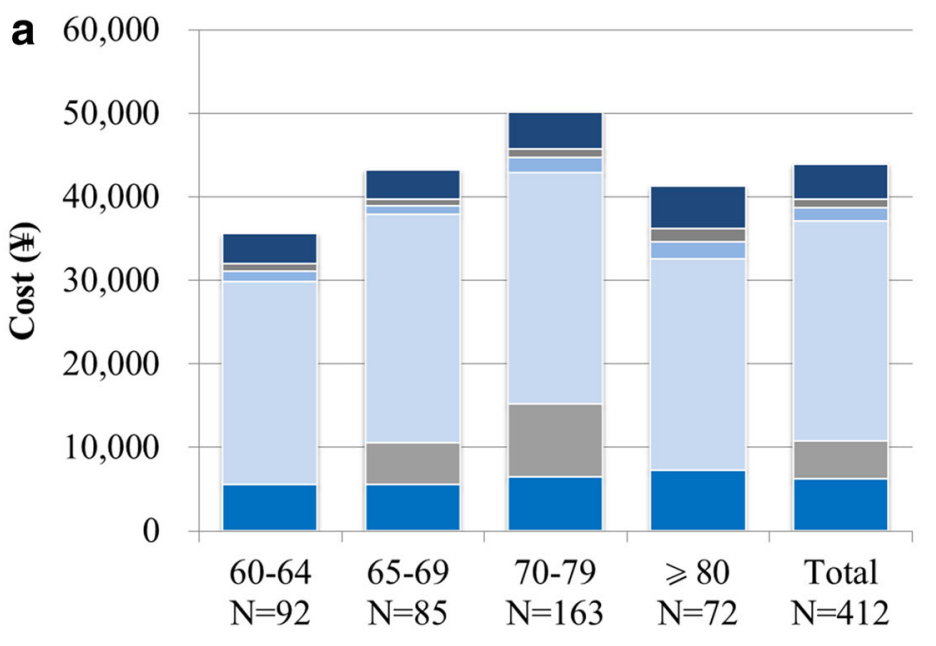

Age

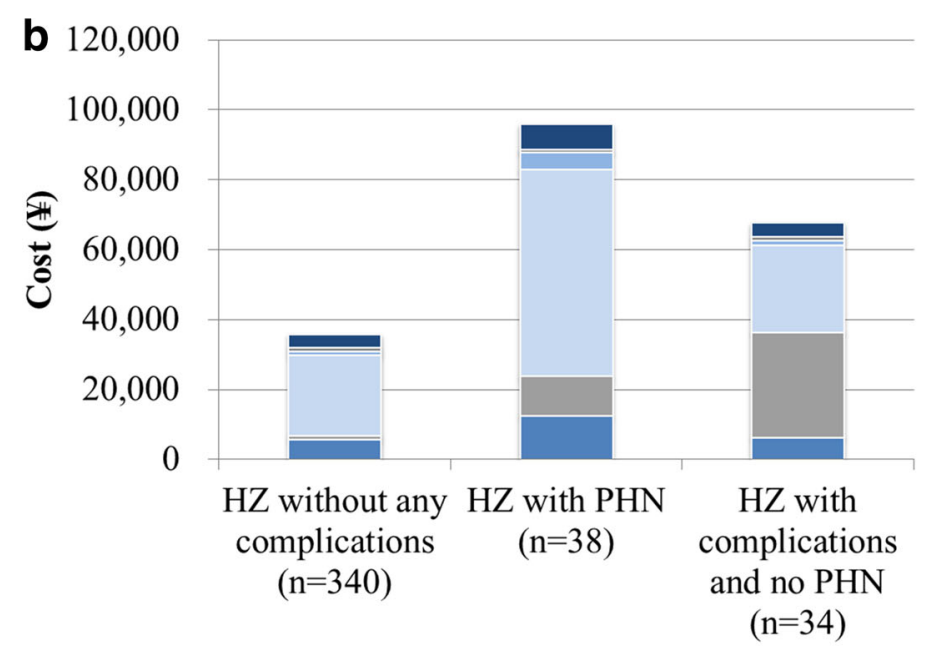

HZ status
- Others

- Ointment treatment

Injections

$\square$ Prescriptions

- Hospitalization

- Outpatient visit
- Others

- Ointment treatment

Injections

- Prescriptions

- Hospitalization

- Outpatient visit
Table 4 Lost work days of patients and their caregivers

\begin{tabular}{llllll}
\hline Age group (years) & $60-64$ & $65-69$ & $70-79$ & $\geq 80$ & Total \\
& $N=92$ & $N=85$ & $N=163$ & $N=72$ & $N=412$ \\
\hline Patients & & & & & \\
$N$ & 11 & 8 & 9 & 0 & 28 \\
$\quad$ Mean (SD) & $4.8(4.00)$ & $6.4(13.26)$ & $12.0(11.78)$ & - & $7.6(10.13)$ \\
Caregivers & & & & & \\
$N$ & 5 & $6^{\mathrm{a}}$ & 14 & 15 & $40^{\mathrm{b}}$ \\
(1) Paid employment & 3 & 4 & 5 & 8 & 20 \\
Mean (SD) & $3.0(2.65)$ & $10.5(10.34)$ & $6.8(10.31)$ & $5.5(5.68)$ & $6.5(7.59)$ \\
(2) Unpaid employment & 1 & 3 & 3 & 2 & 9 \\
$\quad$ Mean (SD) & 1.0 & $7.3(5.13)$ & $25.3(30.83)$ & $2.5(0.71)$ & $11.6(18.88)$ \\
(3) Missing & 1 & 0 & 6 & 5 & 12 \\
Mean (SD) & 1.0 & - & $11.2(8.93)$ & $13.6(23.75)$ & $11.3(15.92)$ \\
\hline
\end{tabular}

$S D$ standard deviation

${ }^{a}$ One patient reported both paid and unpaid status at different visits

b Thirty-seven patients reported 40 caregivers in total 
Fig. 2 Indirect cost (productivity loss) by age group. $N$ number of patients

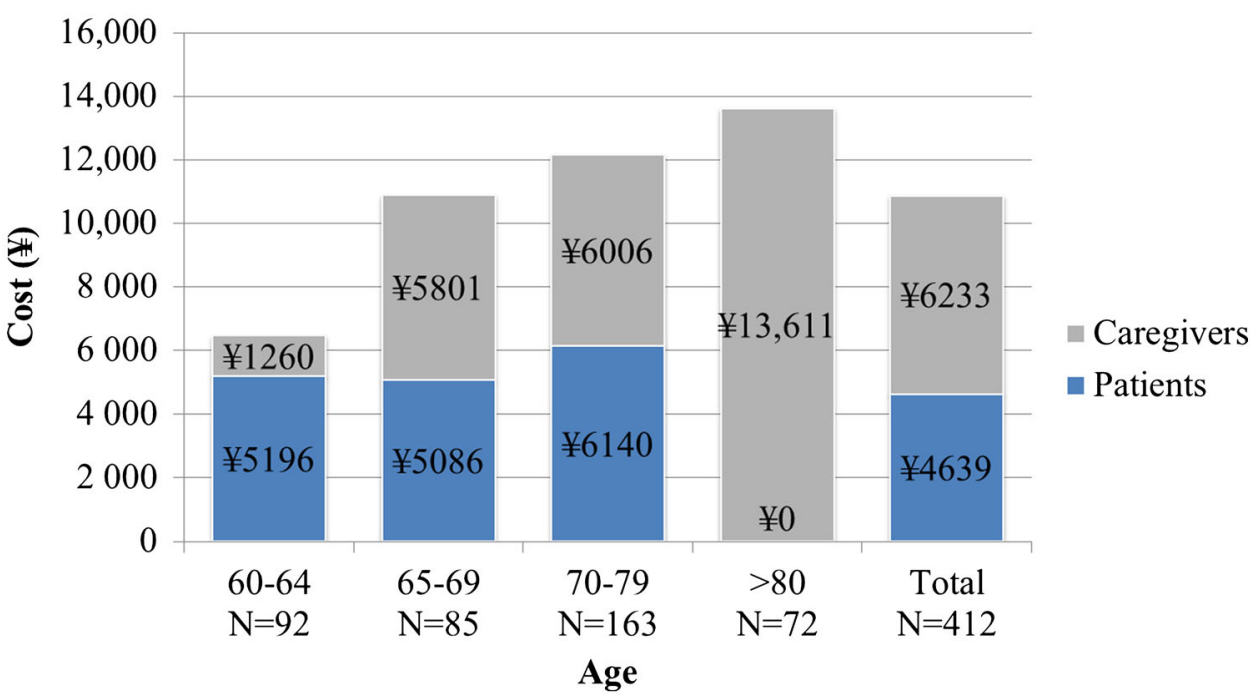

losses were highest in older age groups owing to a higher productivity loss among caregivers.

\subsection{Total Costs from a Payer/Societal Perspective}

From the healthcare system perspective, the total costs equaled the direct medical costs. From the societal perspective, direct medical costs represented $77 \%$, indirect costs 19\%, and transportation costs $4 \%$ of the total (Fig. 3). The average direct medical costs were higher for patients with PHN than for those with HZ without any complications and $\mathrm{HZ}$ with complications and no PHN, although patients with PHN may also have other complications (Table 5). Both the societal and payer costs were higher in patients with PHN and HZ complications than those with HZ only (Table 5).

\section{Discussion}

This prospective, physician practice-based cohort study is the first to estimate the economic burden of $\mathrm{HZ}$ and PHN in Japan. Our results confirmed that HZ imposes a substantial economic burden on the healthcare system as a result of high medical costs related to medications, outpatient visits, and hospitalizations. Patients on average had almost six outpatient visits per $\mathrm{HZ}$ episode, and almost $2 \%$ of the patients were hospitalized, on average for about 9 days. The mean direct medical cost and societal cost was $¥ 43,925$ and $¥ 57,112$ per patient, respectively. In addition, both healthcare payer costs and societal costs were higher in patients with PHN than HZ patients without any complications. The prospective study conducted in Kushiro, Japan [14], reported that $10.2 / 1000$ people would develop $\mathrm{HZ}$ at $\geq 60$ years of age, which would estimate the total annual cases at approximately 430,000 in people aged $\geq 60$ years [4]. Extrapolating our cost data, the estimated total annual economic burden of $\mathrm{HZ}$ in Japan would become $¥ 18,807,613,230$ from the healthcare payer perspective and $¥ 24,453,964,867$ from the societal perspective. Although this burden of around 20 billion yen per year may be underestimated owing to limitations of this study, it is likely that the economic burden will increase substantially in the near future because of an increase in the number of $\mathrm{HZ}$ cases, attributed to the aging Japanese population.

Our finding that direct medical cost was the most important cost item is consistent with results from other studies. A prospective study of $130 \mathrm{HZ}$ cases in patients aged $\geq 14$ years in Spain [6] reported that the cost of $\mathrm{HZ}$ management was $€ 310$ and $€ 378$ from a payer and societal perspective, respectively, and that a majority of the cost was owing to medications, but no hospitalizations for $\mathrm{HZ}$ were observed during that study. In a retrospective claims database study of immunocompetent patients with $\mathrm{HZ}$, Johnson et al. reported that primary cost drivers were outpatient prescriptions and other outpatient services [10]. In addition, our finding that both payer costs and societal costs were higher in patients with PHN than those with $\mathrm{HZ}$ without PHN was consistent with the results of studies in other countries $[6-8,10]$.

Healthcare resource utilization data were collected at each visit by the case report forms and were completed by physicians for this study. Therefore, all the medications reported were included in the study. In Japan, non-steroidal anti-inflammatory drugs or acetaminophen is recommended for acute HZ pain [24]. Neurotropin ${ }^{\circledR}$ is recommended for PHN as well as tricyclic antidepressants, calcium channel alpha-2-delta ligands, and opioids [25]. Indeed, non-steroidal anti-inflammatory drugs, 
Table 5 Total costs from a payer/societal perspective by type of complication and age group

\begin{tabular}{|c|c|c|c|c|c|c|}
\hline \multicolumn{2}{|l|}{ Age group (years) } & $\begin{array}{l}60-64 \\
N=92\end{array}$ & $\begin{array}{l}65-69 \\
N=85\end{array}$ & $\begin{array}{l}70-79 \\
N=163\end{array}$ & $\begin{array}{l}\geq 80 \\
N=72\end{array}$ & $\begin{array}{l}\text { Total } \\
N=412\end{array}$ \\
\hline \multicolumn{7}{|c|}{ (1) Payer perspective (direct medical cost) } \\
\hline \multirow[t]{6}{*}{$\mathrm{HZ}$ without any complications } & $n$ & 83 & 73 & 126 & 58 & 340 \\
\hline & Mean & 32,274 & 36,615 & 38,414 & 33,853 & 35,751 \\
\hline & SD & 16,380 & 35,418 & 25,151 & 20,418 & 25,319 \\
\hline & Min & 13,710 & 13,376 & 4322 & 10,240 & 4322 \\
\hline & Median & 29,553 & 31,182 & 33,602 & 30,081 & 31,411 \\
\hline & Max & 139,712 & 247,457 & 215,379 & 132,270 & 247,457 \\
\hline \multirow[t]{6}{*}{ HZ with PHN } & $n$ & 5 & 7 & 20 & 6 & 38 \\
\hline & Mean & 88,801 & 123,988 & 82,502 & 113,304 & 95,836 \\
\hline & SD & 66,197 & 147,992 & 74,362 & 60,806 & 87,560 \\
\hline & Min & 25,649 & 43,718 & 19,176 & 56,670 & 19,176 \\
\hline & Median & 60,233 & 64,067 & 62,267 & 85,235 & 65,562 \\
\hline & Max & 165,752 & 456,700 & 316,097 & 213,581 & 456,700 \\
\hline \multirow[t]{6}{*}{ HZ with complications, no PHN } & $n$ & 4 & 5 & 17 & 8 & 34 \\
\hline & Mean & 37,795 & 26,184 & 99,415 & 40,965 & 67,643 \\
\hline & SD & 4537 & 14,353 & 128,667 & 44,177 & 97,614 \\
\hline & Min & 33,542 & 10,347 & 19,294 & 16,563 & 10,347 \\
\hline & Median & 36,718 & 22,704 & 41,061 & 29,202 & 33,793 \\
\hline & Max & 44,203 & 49,185 & 463,330 & 148,719 & 463,330 \\
\hline \multirow[t]{6}{*}{ Overall } & $n$ & 92 & 85 & 163 & 72 & 412 \\
\hline & Mean & 35,586 & 43,197 & 50,186 & 41,264 & 43,925 \\
\hline & SD & 24,513 & 56,993 & 57,120 & 35,650 & 48,321 \\
\hline & Min & 13,710 & 10,347 & 4322 & 10,240 & 4322 \\
\hline & Median & 30,568 & 31,581 & 34,044 & 30,574 & 32,755 \\
\hline & Max & 165,752 & 456,700 & 463,330 & 213,581 & 463,330 \\
\hline \multicolumn{7}{|c|}{ (2) Societal perspective (direct medical cost, direct non-medical cost, and indirect cost) } \\
\hline \multirow[t]{6}{*}{ HZ without any complications } & $n$ & 83 & 73 & 126 & 58 & 340 \\
\hline & Mean & 39,941 & 48,396 & 46,110 & 49,373 & 45,652 \\
\hline & SD & 29,068 & 80,806 & 39,621 & 62,499 & 53,281 \\
\hline & Min & 13,974 & 13,442 & 4608 & 10,328 & 4608 \\
\hline & Median & 32,961 & 33,371 & 34,144 & 34,557 & 33,872 \\
\hline & Max & 149,011 & 652,800 & 237,256 & 430,560 & 652,800 \\
\hline \multirow[t]{6}{*}{ HZ with PHN } & $n$ & 5 & 7 & 20 & 6 & 38 \\
\hline & Mean & 106,829 & 137,577 & 151,754 & 145,163 & 142,190 \\
\hline & SD & 75,642 & 152,751 & 159,415 & 81,126 & 136,255 \\
\hline & Min & 25,759 & 48,278 & 23,487 & 58,470 & 23,487 \\
\hline & Median & 78,387 & 76,507 & 72,088 & 125,965 & 80,290 \\
\hline & Max & 213,052 & 480,373 & 602,806 & 259,919 & 602,806 \\
\hline \multirow[t]{6}{*}{$\mathrm{HZ}$ with complications, no PHN } & $n$ & 4 & 5 & 17 & 8 & 34 \\
\hline & Mean & 45,788 & 45,145 & 103,093 & 55,495 & 76,630 \\
\hline & SD & 12,438 & 55,188 & 131,858 & 57,734 & 101,265 \\
\hline & Min & 36,674 & 10,479 & 19,426 & 18,954 & 10,479 \\
\hline & Median & 41,512 & 22,902 & 46,561 & 34,303 & 37,081 \\
\hline & $\operatorname{Max}$ & 63,454 & 143,201 & 483,130 & 188,319 & 483,130 \\
\hline Overall & $n$ & 92 & 85 & 163 & 72 & 412 \\
\hline
\end{tabular}


Table 5 continued

\begin{tabular}{|c|c|c|c|c|c|c|}
\hline \multicolumn{2}{|l|}{ Age group (years) } & $\begin{array}{l}60-64 \\
N=92\end{array}$ & $\begin{array}{l}65-69 \\
N=85\end{array}$ & $\begin{array}{l}70-79 \\
N=163\end{array}$ & $\begin{array}{l}\geq 80 \\
N=72\end{array}$ & $\begin{array}{l}\text { Total } \\
N=412\end{array}$ \\
\hline & Mean & 43,830 & 55,549 & 65,016 & 58,036 & 57,112 \\
\hline & SD & 35,355 & 89,555 & 85,252 & 68,055 & 75,138 \\
\hline & Min & 13,974 & 10,479 & 4608 & 10,328 & 4608 \\
\hline & Median & 33,609 & 34,062 & 36,982 & 35,560 & 35,229 \\
\hline & Max & 213,052 & 652,800 & 602,806 & 430,560 & 652,800 \\
\hline
\end{tabular}

$H Z$ herpes zoster, Max maximum, Min minimum, $P H N$ post-herpetic neuralgia, $S D$ standard deviation

Fig. 3 Total costs by age group. $N$ number of patients

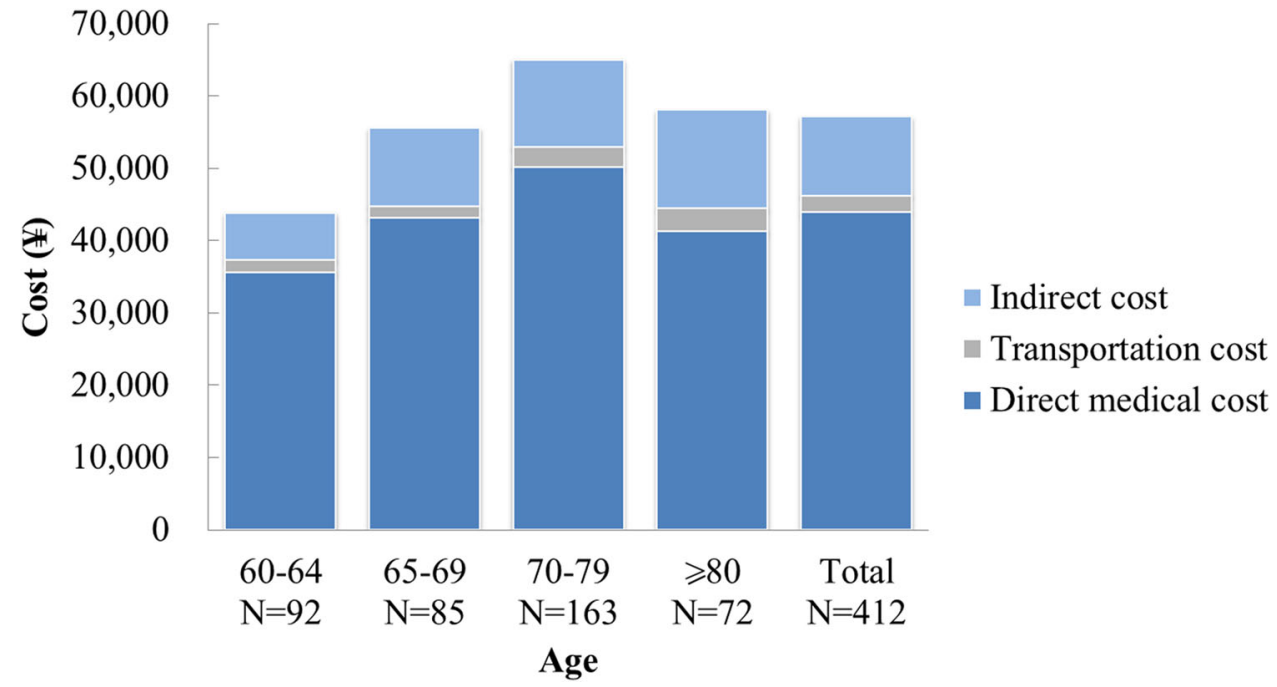

acetaminophen, pregabalin, and Neurotropin ${ }^{\circledR}$ have been reported as frequently used PHN treatments [25]. The treatment pattern in our study was similar to this. Although the average number of outpatient visits owing to $\mathrm{HZ}$ has been reported at approximately two to four visits $[6,7,9,10]$, a higher number of visits (5.7 times) was observed in our study. An increased number of patients receiving a Neurotropin ${ }^{\circledR}$ injection would contribute to this increase in outpatient visits, as well as the difference in Japanese healthcare systems in comparison to other countries.

According to the Centers for Disease Control and Prevention, the HZ hospitalization rate is reported at approximately $1-4 \%$ in USA [26]. Hospitalization costs contribute significantly to the overall direct cost of managing $\mathrm{HZ}$ and PHN. In other studies, data on hospitalizations and inpatient costs were primarily extracted from a range of national and insurance databases in each country $[7,8,11]$. In our study, $1.9 \%$ of the $\mathrm{HZ}$ patients were hospitalized while a higher rate of hospitalizations (3.4\%) was previously reported in Japan [14]. As $1.9 \%$ was used in cost analyses, the costs related to hospitalization, and consequently, the overall costs may have been underestimated. Indeed, it has been reported that the proportion of hospitalization costs compared with total $\mathrm{HZ}$ costs decreased from 72.9 to $48.5 \%$ owing to a dramatic drop in the rate of hospitalization [27]. In addition, although hospitalization rates for patients with $\mathrm{HZ}$ has been reported to increase with age [7, 10, 11], only two patients aged 65-69 years and six patients aged 70-79 years were hospitalized in this study. Therefore, we were unable to draw a conclusion on age-related differences in hospitalization rates. Although the direct medical costs were reported to increase over the age of 60 years [10, 11], overall direct medical costs and medication costs were highest in the 70-79 year age group; this also seemed to be owing to the higher number of hospitalizations observed in this age group. Further research using a large-scale database is required in Japan to elucidate the impact of HZ- and PHNrelated hospitalizations on the economic burden of the diseases by age and immune conditions. 
In a prospective population-based study in the UK, HZ in elderly patients was associated with low indirect costs owing to fewer work absences [28]. The indirect cost in $\mathrm{HZ}$ patients aged $<65$ years and $\geq 65$ years was 82 and $15 \%$, respectively, of the societal cost [28]. Our study including $\mathrm{HZ}$ patients aged $\geq 60$ years demonstrated that indirect costs had a relatively low impact on the economic burden of HZ (19\% of the total societal cost). Only $23 \%$ of the study population, or $53.2 \%$ of those aged $60-64$ years and $14.3 \%$ of those aged $\geq 65$ years, were employed at the time of the study and $30 \%$ of the employed patients reported that they were absent from work owing to HZ, for an average of 7.6 days. The labor force participation rates in Japan for people aged 60-64 years and $\geq 65$ years were reported at $62.8 \%$ and $21.2 \%$, respectively, in 2014 [29]. A lower employment rate in our study population than in the overall Japanese population would also contribute to the low costs reported. Productivity loss for caregivers increased with the patients' age because elderly patients required more care services.

However, comparisons of results from studies performed in different countries are fraught with difficulties and must be interpreted cautiously because of differences in healthcare practices, pricing, and the development level of the country. Furthermore, it has been recognized that various factors such as the lack of a universally accepted definition of PHN, the study design (prospective vs. retrospective, population- vs. cohort- or claims databasebased), and the demographic and clinical features of the patients included can influence the findings of studies [13].

The direct medical cost may have been underestimated because healthcare resource utilization data were collected for a time period limited to a maximum of 270 days after the initial visit. Patients without HZ-related pain were not followed after 90 days but may have continued to use HZrelated medical resources after this time point. Likewise, patients with persistent PHN after 270 days may also have continued using medical resources after the cut-off of the follow-up as previously reported [30]. The healthcare resource utilization data were only collected from the study sites. If the patients were referred to other sites, only the referral fee was added. Medical costs during hospitalization were estimated based on DPC/PDPS because of difficulties in collecting detailed hospital resource utilization data. Regardless of the actual treatment given, the hospitalization cost per day was fixed. The enrolled patients were limited to those who agreed to give written informed consent and could respond to the questionnaire survey. Consequently, patients with very severe $\mathrm{HZ}$ and $\mathrm{HZ}$ patients with rare complications may not have been enrolled.

\section{Conclusion}

This is the first study to estimate the economic burden of $\mathrm{HZ}$ and PHN in Japan. Direct medical cost was the main cost driver for HZ-related costs and was mostly related to prescription medications. It may be expected that the economic burden of $\mathrm{HZ}$ and PHN will grow substantially owing to an increase in the number of $\mathrm{HZ}$ cases in the aging Japanese population. The information reported here provides baseline data for potential future economic evaluations of new interventions against $\mathrm{HZ}$ and PHN.

Acknowledgements The authors thank Kenji Iida (investigator, dermatologist) and Business \& Decision Life Sciences (on behalf of GSK) for editorial assistance and manuscript coordination. Gregory Collet coordinated manuscript development and editorial support, and John Bean (Bean Medical Writing) provided medical writing services.

Authors' Contributions HN, AM, K. Adachi, KH, KS, TK, and DC conceived the design of the study. HN, K. Adachi, K. Asano, AW, RA, MK, KK, and TM collected or generated the study data. SM and DC analyzed the data. HN, AM, K. Adachi, KH, K. Asano, AW, RA, MK, KK, and DC interpreted the data.

\section{Compliance with Ethical Standards}

Funding GlaxoSmithKline Biologicals SA funded the study and was involved in all study activities and overall data management (collection, analysis, and interpretation), and funded all costs associated with developing and publishing this article. All authors had full access to the data, and the corresponding author was responsible for submission of the publication.

Conflict of interest K. Adachi and K. Asano reported a study grant and personal fees for medical advice from the GSK group of companies during the conduct of the study and personal fees for lectures from the GSK group of companies outside the submitted work. RA and MK reported a study grant and personal fees for medical advice from the GSK group of companies during the conduct of the study. HN reported a study grant, personal fees for medical advice, and travel support to a congress presentation from the GSK group of companies during the conduct of the study. KK reported a study grant from the GSK group of companies during the conduct of the study. AW reported a study grant from the GSK group of companies during the conduct of the study and personal fees for lectures from the GSK group of companies outside the submitted work. KH, DC, KS, and TK are employees of the GSK group of companies and hold stock options or restricted shares. TM and AM are employees of the GSK group of companies. SM is a freelance consultant working on behalf of the GSK group of companies. KS, TK, TM, and AM received funding from Japan Vaccine Co. Ltd. (a 50\%/50\% Joint Venture of GSK/ Daiichi Sankyo Company, Ltd.) for the conduct of the study.

Consent to participate Informed consent was obtained from all individual participants included in the study.

Ethics approval All procedures performed in studies involving human participants were in accordance with the ethical standards of the institutional and/or national research committee and with the 1964 Helsinki Declaration and its later amendments or comparable ethical standards. The study was reviewed by the Ethics Committee of 
Kushiro City General Hospital, Kushiro Red Cross Hospital, or Clinical Research Hospital Tokyo.

Data availability The cost data were collected as part of an observational, prospective, physician practice-based cohort study of people 60 years of age or older conducted in Kushiro, Japan between June 2013 and February 2015. The details of the study are published elsewhere.

Trademark Neurotropin ${ }^{\circledR}$ is a trademark of the Nippon Zoki Pharmaceutical Co. Ltd, Japan.

Open Access This article is distributed under the terms of the Creative Commons Attribution-NonCommercial 4.0 International License (http://creativecommons.org/licenses/by-nc/4.0/), which permits any noncommercial use, distribution, and reproduction in any medium, provided you give appropriate credit to the original author(s) and the source, provide a link to the Creative Commons license, and indicate if changes were made.

\section{References}

1. National Institute of Infectious Diseases. Infectious agents surveillance report (IASR). 2016. Available from: http://www. niid.go.jp/niid/ja/iasr.html. Accessed 25 Aug 2017.

2. Centers for Disease Control and Prevention. Shingles (herpes zoster). 2016. Available from: http://www.cdc.gov/shingles/ about/overview.html. Accessed 25 Aug 2017.

3. Takao Y, Miyazaki Y, Okeda M, Onishi F, Yano S, Gomi Y, et al. Incidences of herpes zoster and postherpetic neuralgia in Japanese adults aged 50 years and older from a community-based prospective cohort study: the SHEZ Study. J Epidemiol. 2015;25:617-25.

4. Official Statistics of Japan. Total population, October 1, 2014. Available from: http://www.e-stat.go.jp. Accessed 25 Aug 2017.

5. United Nations. Population ageing and development. 2012. Available from: http://www.un.org/esa/population/publications/ 2012PopAgeingDev_Chart/2012PopAgeingandDev_WallChart. pdf. Accessed 25 Aug 2017.

6. Cebrián-Cuenca A, Díez-Domingo J, San-Martín-Rodríguez M, Puig-Barberá J, Navarro-Pérez J. Epidemiology and cost of herpes zoster and postherpetic neuralgia among patients treated in primary care centres in the Valencian community of Spain. BMC Infect Dis. 2011;11:302.

7. Gialloreti L, Merito M, Pezzotti P, Naldi L, Gatti A, Beillat M, et al. Epidemiology and economic burden of herpes zoster and post-herpetic neuralgia in Italy: a retrospective, population-based study. BMC Infect Dis. 2010;10:230.

8. Ultsch B, Köster I, Reinhold T, Siedler A, Krause G, Icks A, et al. Epidemiology and cost of herpes zoster and postherpetic neuralgia in Germany. Eur J Health Econ. 2013;6:1015-26.

9. Gater A, Uhart M, McCool R, Préaud E. The humanistic, economic and societal burden of herpes zoster in Europe: a critical review. BMC Public Health. 2015;15:193.

10. Johnson B, Palmer L, Gatwood J, Lenhart G, Kawai K, Acosta C. Healthcare resource utilization and costs associated with herpes zoster in the US. J Med Econ. 2016;19:928-35.

11. Lin Y, Huang L, Chang I, Tsai F, Lu C, Shao P, et al. Disease burden and epidemiology of herpes zoster in pre-vaccine Taiwan. Vaccine. 2010;28:1217-20.

12. Aunhachoke K, Bussaratid V, Chirachanakul P, Chua-Intra B, Dhitavat J, Jaisathaporn K, et al. Measuring herpes zoster, zosterassociated pain, post-herpetic neuralgia-associated loss of quality of life, and healthcare utilization and costs in Thailand. Int $\mathbf{J}$ Dermatol. 2011;50:428-35.

13. Panatto D, Bragazzi N, Rizzitelli E, Bonanni P, Boccalini S, Icardi $\mathrm{G}$, et al. Evaluation of the economic burden of herpes zoster (HZ) infection. Hum Vaccin Immunother. 2015;11:245-62.

14. Sato K, Adachi K, Nakamura H, Asano K, Watanabe A, Adachi $\mathrm{R}$, et al. Burden of herpes zoster and postherpetic neuralgia in Japanese adults 60 years of age or older: results from an observational, prospective, physician practice-based cohort study. J Dermatol. 2017;44:414-22.

15. Coplan P, Schmader K, Nikas A, Chan I, Choo P, Levin M, et al. Development of a measure of the burden of pain due to herpes zoster and postherpetic neuralgia for prevention trials: adaptation of the brief pain inventory. J Pain. 2004;5:344-56.

16. Ministry of Education Culture, Sports, Science and Technology and Ministry of Health Labour and Welfare. Ethical guidelines for epidemiological research. Available from: http://www.mhlw. go.jp/seisakunitsuite/bunya/hokabunya/kenkyujigyou/i-kenkyu/ dl/02-02.pdf. Accessed 25 Aug 2017.

17. Japanese Ministry of Health Labour and Welfare. The 2014 revision of medical payment system. Available from: http://www. mhlw.go.jp/stf/seisakunitsuite/bunya/0000032996.html. Accessed 25 Aug 2017.

18. Japanese Ministry of Health Labour and Welfare. List of price standards for medicines. Available from: http://www.mhlw.go.jp/ topics/2016/04/tp20160401-01.html. Accessed 25 Aug 2017.

19. Taxisite. Available from: http://www.taxisite.com/far/info/1. aspx. Accessed 25 Aug 2017.

20. Agency for Natural Resources and Energy. Available from: http://www.enecho.meti.go.jp/statistics/petroleum_and_lpgas/. Accessed 25 Aug 2017.

21. Kushiro Bus. Available from: http://www.kushirobus.jp/index. html. Accessed 25 Aug 2017.

22. JR-Odekake. Available from: http://www.jr-odekake.net/railroad/ ticket/guide/02.html\#030. Accessed 25 Aug 2017.

23. Official Statistics of Japan. The basic survey of wage structure. 2013. Available from: http://www.e-stat.go.jp/SG1/estat/ eStatTopPortal.do. Accessed 25 Aug 2017.

24. Watanabe D, Asano Y, Ito H, Kawai Y, Kawashima M, Shimomura Y, et al. Expert consensus on herpes zoster: diagnosis, treatment and prevention. J Clin Ther Med. 2012;28:161-73.

25. Honda M, Murata T, Ebata N, Fujii K, Ogawa S. Treatment patterns of postherpetic neuralgia patients before and after the launch of pregabalin and its effect on medical costs: analysis of Japanese claims data provided by Japan Medical Data Center. J Dermatol. 2017;44:767-73.

26. Centers for Disease Control and Prevention. Shingles (herpes zoster): clinical overview. 2016. Available from: http://www.cdc. gov/shingles/hcp/clinical-overview.html. Accessed 25 Aug 2017.

27. Friesen K, Chateau D, Falk J, Alessi-Severini S, Bugden S. Cost of shingles: population based burden of disease analysis of herpes zoster and postherpetic neuralgia. BMC Infect Dis. 2017;17:69.

28. Scott F, Johnson R, Leedham-Green M, Davies E, Edmunds W, Breuer J. The burden of herpes zoster: a prospective population based study. Vaccine. 2006;24:1308-14.

29. Official Statistics of Japan. Survey of labour force. 2014. Available from: http://www.e-stat.go.jp/SG1/estat/ eStatTopPortal.do. Accessed 25 Aug 2017.

30. Friesen K, Falk J, Alessi-Severini S, Chateau D, Bugden S. Price of pain: population-based cohort burden of disease analysis of medication cost of herpes zoster and postherpetic neuralgia. J Pain Res. 2016;9:543-50. 